EESTI NSV TEADUSTE AKADEEMIA TOIMETISED. 31. KOIDE

FOOSIKA * MATEMAATIKA. 1982, NR. 2

ИЗВЕСТИЯ АКАДЕМИИ НАУК ЭСТОНСКОП ССР. ТОМ 31 ФИЗИКА * МАТЕМАТИҚА. 1982, № 2

\title{
МОДЕЛЬ ПРЕВРАЩЕНИЯ ЦЕНТРОВ ПРИ ВЫЖИГАНИИ ПРОВАЛА В СПЕКТРАХ ХЛОРОФИЛЛА
}

K достоинствам метода выжигания провала $\left[{ }^{1,2}\right]$ относится возможность изучения низкотемпературной фотохимии примесных молекул. $\mathrm{y}$ некоторых молекул микроскопический механизм фотохимии расшифрован (хорошим примером является фототаутомерия соединений с порфинным кольщом) и химические формы примесей различимы по спектру поглощения $\left[{ }^{3-5}\right]$. Однако у многих больших органических молекул, обладающих обратимой фотохимией в твердых матрицах, при выжигании провала не наблюдается новых полос поглощения и механизм выжигания не так легко объясним $\left[{ }^{6-9}\right]$. К таким соединениям относится и хлорофилл $\left[{ }^{10}\right]$. При объяснении механизмов выжигания в таких случаях обычно ограничиваются общим предположением о спектральном перераспределении примесных центров в неоднородной полосе $[9,10]$. Единственная более детальная интерпретация такого перераспределения имеется в $\left[{ }^{11,12}\right]$, где оно связывается со свойствами аморфных матриц.

В настоящей работе показано, что превращение центров, приводящее к распределению их в пределах неоднородной полосы, действительно имеет место у хлорофилла в замороженных растворах, и исследованы некоторые свойства этого явления.

Провал выжигался в чисто электронной полосе спектров возбуждения при регистрации на колебательных повторениях. Спектральная полоса для регистрации выделялась с помощью монохроматора МДР-2, возбуждение осуществлялось лампой накаливания через монохроматор спектрометра ДФС-24 (спектральная ширина щелей $3 \mathrm{~cm}^{-1}$ ). Для выжигания использовались криптоновый лазер CR-2000K и лазер на красителе (родамин 101) фирмы «Spectra-Physics», модель 375.

На рис. 1 показаны спектры возбуждения хлорофиллฺа $a$ в эфирбутаноле (в соотношении $5: 2$ по объему) до и после облучения образца лазерным светом. В темноте искаженная форма спектра была стабильной - восстановления не наблюдалось в течение многих часов.

Объяснить такие изменения формы спектра позволяет предположение, что у примесных центров имеются разные равновесные конфигурации (в общем случае с разными частотами электронного перехода), между которыми возможны оптически индуцированные переходы. На рис. 1 видно образование провала, форма которого напоминает вид однородного спектра. Узкий провал на длине волны лазера возникает из-за уменьшения числа резонансно-поглощающих центров, которые, перейдя между своими конфигурациями, станут поглощать на другой длине волны. Широкий провал в длинноволновой стороне от линии лазера возникает из-за уменьшения числа центров, которые поглощают через фононные крылья.

На другой стороне от узкого провала сигнал увеличивается - сюда 


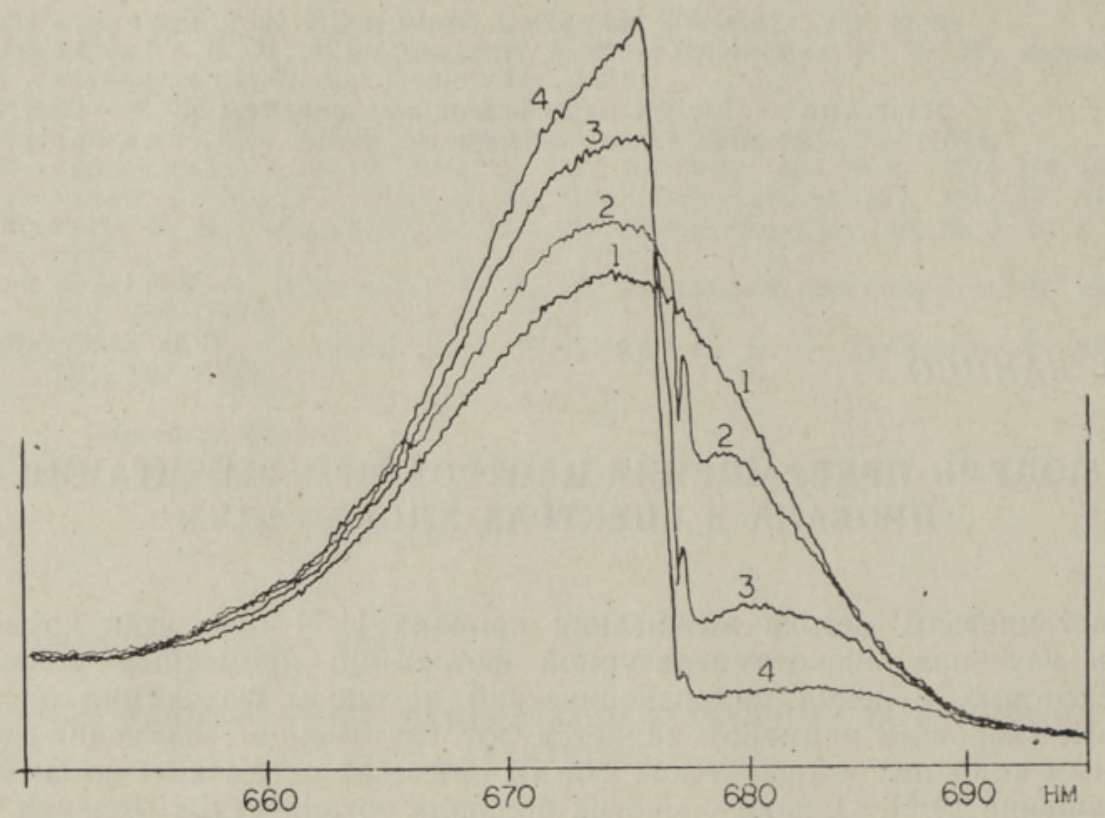

Рис. 1. Спектры возбуждения хлорофилла а в эфир-бутаноле до (1) и после выжигания линией $676,4 \mathrm{m \mu}$ в течение 0.5 (2), 5 (3) и 30 мин (4). Интен-

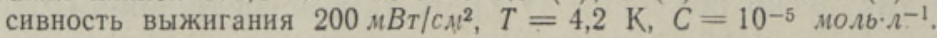

и приходят выжигаемые центры из провала*. Накопление примесных центров в этом спектральном интервале связано с тем, что при гелиевых температурах антистоксовая часть фононного крыла практически отсутствует и, следовательно, центры, частота электронного перехода которых оказывается после перехода между конфигурациями больше частоты лазера, в дальнейшем не возбуждаются.

Форма измеренных спектров позволяет сделать следующие замечания о равновесных конфигурациях и переходах между ними. Во-первых, при большой дозе облучения большинство из поглощающих центров покидает свои места. Из этого можно заключить, что у них много возможных позиций в неоднородной полосе, т. е. много равновесных конфигураций. Ведь если бы их было мало (напр., две, как обычно при внутрипримесной фотохимии), то часть центров (при выжигании в центре полосы - примерно половина из них) зацеплялась бы в спектральном интервале, где они поглощают, и спектр не претерпевал бы таких больших изменений. Во-вторых, так как изменение спектра в результате накопления центров в спектральном интервале, где они не поглощают, примерно пропорционально первоначальной форме спектра, можно утверждать, что на перераспределение влияют статистические условия, подобные тем, которые обусловили первоначальный контур неоднородного распределения. В-третьих, у многих примесных центров должны быть конфигурации с разностью частот электронного перехода порядка $100 \mathrm{~cm}^{-1}$. Тем самым для объяснения наших результатов механизм, предложенный в $\left[{ }^{11,12}\right]$, не годится: он допускает спектральные сдвиги лишь порядка $1 \mathrm{~cm}^{-1}$.

Такие же изменения обнаружены в неоднородных спектрах возбуждения $\mathrm{Zn}$-феофитина и протохлорофилла в эфире и хлорофилла $a$ в

* Как известно $\left[{ }^{8,13}\right]$, в случае переходов между двумя спектрально отдаленными конфигурациями в спектре возбуждения и здесь должен возникнуть широкий провал. В данном случае это замаскировано перераспределением центров (см. также [14]). 


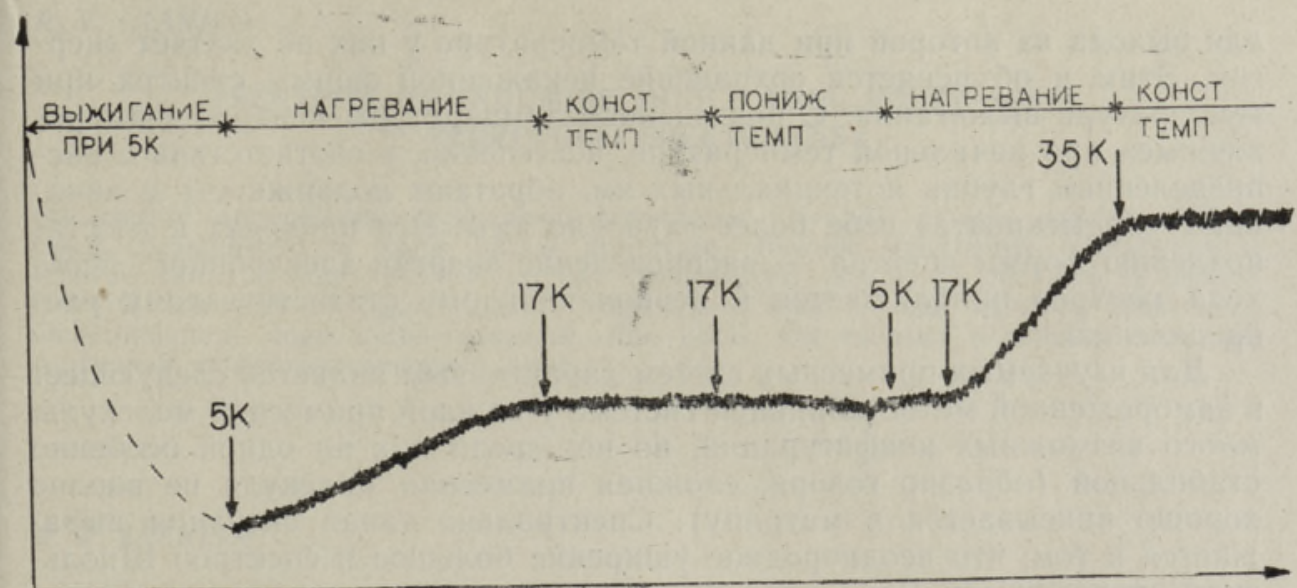

Рис. 2. Изменение интенсивности флуоресценции хлорофилла $a$ в эфир-бутаноле из-за темнового восстановлення при возбуждении на длине волны 678 нм.

эфире и $н$-гептане. Изменчивая спектральная неоднородность наблюдалась нами и у феофитина в эфире, но из-за одновременного возникновения фототаутомерии $\left[{ }^{4}\right]$ исследование эффектов перераспределения в этой системе оказалось затруднительным.

Квантовый выход изучаемых процессов превращения центров при температуре $4,2 \mathrm{~K}$ оценивался нами порядка $10^{-4}-10^{-5}$. Если сравнить примесные системы в стеклообразной и поликристаллической матрице, то в последней из них процессы были в несколько раз менее эффективными.

Спектр, который был изменен монохроматическим излучением, восстановился (т. е. приобрел опять колоколообразную форму) под влиянием «белого» излучения или же в темноте с повышением температуры. C другой стороны, при выжигании и измерении спектра при одной и той же температуре не было замечено темнового восстановления формы спектра при всех температурах от 4,2 до $70 \mathrm{~K}$.

Для изучения активационных энергий процессов, которые изменяют структуру примесного центра в основном состоянии, мы поступили следующим образом. Сначала изменили форму спектра путем выжигания при температуре $5 \mathrm{~K}$ (изучаемой системой был хлорофилл $а$ в эфирбутаноле. и выжигание осуществляли линией 676,4 нм криптонового лазера). Затем начали повышать температуру, и зарегистрировали сигнал при возбуждении в области «крыла» провала (на длине волны 678 нм). Из рис. 2 видно, что спектр стал восстанавливаться сразу же после повышения температуры выше $5 \mathrm{~K}$. С прекращением ее повышения немедленно прекратилось и увеличение сигнала, т. е. форма спектра перестала восстанавливаться из-за перераспределения центров в основном состоянии. Сигнал оставался константным и при дальнейшем понижении температуры, но опять увеличивался, когда температура превышала ту, при которой прекратили нагревание.

Описанный характер восстановления спектра указывает на широкое распределение энергий активации для процессов в основном состоянии. Мы предполагаем, что многие равновесные состояния, которые присущи каждому примесному центру, локализованы в потенциальных ямах разной глубины. При оптическом возбуждении системы те из примесных центров, которые возвращаются в основное состояние после перехода между конфигурациями, частично попадают в потенциальные ямы относительно малой глубины. Они быстро релаксируются в глубокую яму, 
для выхода из которой при данной температуре у них не хватает энергии. Этим и объясняется сохранение искаженной формы спектра при температуре выжигания. С повышением температуры центры, «замороженные» при начальной температуре, постепенно, в соответствии с распределением глубин потенциальных ям, обретают подвижность и начинают «подыскивать» себе более глубокие ямы. Это приводит к восстановлению формы спектра - распределение энергии электронного перехода центров приближается к первоначальному статистическому распределению.

Для изучаемых примесных систем характерным является следующее: в замороженной метастабильной системе у каждой примесной молекулы много возможных конфигураций, но нет среди них ни одной особенно стабильной (образно говоря, сложная примесная молекула не вполне хорошо вписывается в матрицу). Спектрально такая ситуация выражается в том, что неоднородное уширение большое и спектров Шпольского не возникает. Ясно, что при не слишком малых вероятностях переходов между конфигурациями и должны проявляться эффекты перераспределения. Механизм выжигания провала, обусловленный таким общим характером взаимодействия примеси с матрицей, может работать и у других больших органических молекул в твердых матрицах.

Автор блағодарен Р. А. Авармаа за внимание к работе и обсуждение ее результатов, Я. В. Кикасу за ценные замечания и К. Х. Маурингу за участие в экспериментах.

\title{
ЛИТЕРАТУРА
}

1. Гороховский А. А., Ка арли Р. К., Ребане Л. А., Письма в ЖЭТФ, 20, вып. 7, 474-479 (1974).

2. Kharlamov, B. M., P e r s onov, R. I., Bykovskaya, L. A., Opt. Commun., 12, № 2, 191-193 (1974).

3. Vöelker, S., van der Wa als J. H., Mol. Phys., 32, № 6, 1703-1718 (1976).

4. Avarmaa, R., Mauring, K., Chem. Phys. Lett., 81, № 3, 446-449 (1981).

5. Drissler, F., Graf, F., Ha arer, D., J. Chem. Phys., 72, № 9, 4996-5001 (1980).

6. Gutierrez, A. R., Chem. Phys. Lett.. 74, № 2, 293-297 (1980).

7. Харламов Б. М., Персонов Р. И., Быковская Л. А., Оптика и спектроскопия, 39, вып. 2, 240-247 (1975).

8. Kharlamov, B. M., Bykovskaya, L. A., Personov, R. I., Chem. Phys. Lett., 50, № 3, 407-411 (1977).

9. Cuell a r, E., Castro, G., Chem. Phys., 54, № 2, 217-225 (1981).

10. Avarmaa, R., Mauring, K., Suisalu, A., Chem. Phys. Lett., 77, № 1, $88-92(1981)$.

11. H a yes, J. M., Sma 11, G. J., Chem. Phys., 27, № 1, 151-157 (1978).

12. H a y e s, J. M., S m a 11, G. J., Chem. Phys. Lett,, 54, № 3, 435-438 (1978).

13. К и к а с Я. В., Автореф. канд. дис., Тарту, 1979.

14. М а ур и н г К. Х., А в а р м а а Р. А. (см. настоящий номер).

\author{
Ннститут физики \\ Академии наук Эстонской ССР
}




\section{TSENTRITE MUUNDUMISE MUDEL AUGU FOLETAMISEL KLOROFOLLI SPEKTRITESSE}

On uuritud augupõletuse mehhanismi kü'mutatud klorofülli lahuste spektrites. Muutused ergastusspektrite kujus pärast uuritavate objektide mõjutamist laserkiirgusega lubavad väita, et augu teke on tingitud üleminekutest (saagisega $10^{-4}-10^{-5}$ ) lisanditsentrite erinevate konfiguratsioonide vahel maatriksis. Toimub tsentrite spektraalne ümberjaotumine kogu mittehomogeense riba piires. On esitatud põhiolekus toimuvate protsesside aktivatsioonienergiate jaotus.

R. V. JAANISO

\section{A MODEL OF SITE INTERCONVERSIONS AT HOLE-BURNING IN.THE SPECTRA OF CHLOROPHYLL}

The present investigation was made to get an insight into the nature of the holeburning mechanism in the spectra of chlorophyll in frozen solutions. Under laser radiation the changes in the shape of inhomogeneous spectra emerge, which may be interpreted as a result of transitions (quantum yield $10^{-4}-10^{-5}$ ) between a number of spectrally unequivalent configurations of impurity centres. The centres are redistributed over the whole range of inhomogeneous band. A broad distribution of barriers for the processes in the ground state is observed. 